\title{
PENGOLAHAN EFFLUENT FERMENTOR BIOGAS SECARA AEROBIK MENGGUNAKAN REAKTOR ALIR TANGKI BERPENGADUK
}

\author{
Yohannes Tandean*, Michael Vincent, Irvan, Bambang Trisakti \\ Departemen Teknik Kimia, Fakultas Teknik, Universitas Sumatera Utara \\ Jl. Almamater Kampus USU Medan 20155 Indonesia \\ *Email : demoniacz@ @students.usu.ac.id
}

\begin{abstract}
Abstrak
Produksi minyak kelapa sawit di Indonesia saat ini diperkirakan sekitar 28 juta ton/tahun. Seiring dengan meningkatnya produktivitas ini, maka limbah yang dihasilkan oleh proses pengolahannya yaitu palm oil mill effluent (POME) juga akan semakin meningkat. Di Indonesia, pengolahan POME saat ini dilakukan secara konvensional yaitu dengan menggunakan sistem kolam fakultatif yang selain memerlukan biaya operasional yang tinggi serta lahan yang luas, juga menghasilkan gas rumah kaca, metana $\left(\mathrm{CH}_{4}\right)$ sebagai produk yang biasanya dibuang begitu saja dengan cara dibakar. Dari penelitian terdahulu, dilakukan pengolahan POME secara anaerobik guna menghasilkan biogas, tetapi hasil pengolahannya masih belum memenuhi baku mutu untuk dapat dibuang ke lingkungan, sehingga masih diperlukan proses aerobik agar dapat memenuhi baku mutu yang telah ditetapkan agar dapat dibuang ke lingkungan. Dari hasil penelitian yang telah dilakukan dengan menggunakan reaktor alir tangki berpengaduk dan dengan bantuan effective microorganism (EM4), diperoleh nilai akhir VSS adalah sekitar $100 \mathrm{mg} / \mathrm{L}$ dengan HRT 10 hari.
\end{abstract}

Kata kunci: Biogas, reaktor alir tangki berpengaduk, limbah cair pabrik kelapa sawit, effective microorganism

\begin{abstract}
Palm oil production in Indonesia is estimated around 28 million tonnes per annum. As this number increases, the waste generated from the process which generally called as palm oil mill effluent (POME) increases as well. In Indonesia, POME treatment is being carried out conventionally by using facultative ponds system, which is high in operational cost, uses up a vast amount of land and generates greenhouse gas, Methane $\left(\mathrm{CH}_{4}\right)$ as product which is usually burnt away. From previous researches done, POME has been treated anaerobically to produce biogas, but the effluent from these processes have not yet met the standard quality control required to be released to the environment. Which is why it still needs to be treated aerobically to fulfill the standar quality control so as to be released to the environment. From the research done by using continuous stirred tank reaktor and adding effective microorganism (EM4), the final VSS value reached was around $100 \mathrm{mg} / \mathrm{L}$ with 10 days $H R T$.
\end{abstract}

Keywords : Biogas, continuous stirred tank reaktor, palm oil mill effluent, effective microorganism

\section{Pendahuluan}

Kelapa sawit merupakan salah satu tanaman perkebunan yang mempunyai peranan sangat penting dalam upaya peningkatan pendapatan dan kesejahteraan petani. Industri kelapa sawit merupakan salah satu industri yang berkembang pesat pada dua dekade terakhir dan diproyeksikan masih akan tetap mejadi salah satu primadona dalam sub sektor perkebunan pada masa mendatang [3].

Sejak tahun 2005, pangsa konsumsi minyak kelapa sawit terhadap konsumsi minyak nabati dunia telah menggeser pangsa konsumsi minyak nabati lainnya. Hal itu disebabkan oleh luas lahan yang digunakan untuk menghasilkan minyak nabati jauh lebih besar daripada minyak kelapa sawit [2].

Saat ini Indonesia adalah penghasil minyak kelapa sawit terbesar di dunia seperti yang terlihat pada Gambar 1.

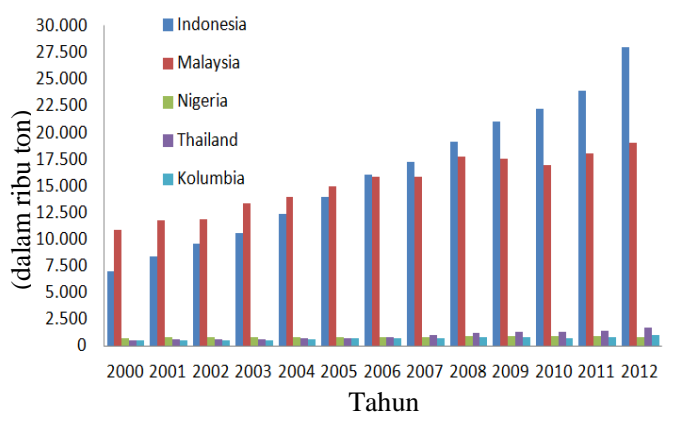

Gambar 1. Perbandingan Produksi Minyak Kelapa Sawit di Dunia[6]

Seiring dengan peningkatan produktivitas kelapa sawit, diikuti juga peningkatan limbah yang dihasilkan dari proses pengolahannya yaitu Palm Oil Mill Effluent (POME). Pengolahan POME secara anaerobik dapat menghasilkan biogas. Tetapi, hasil pengolahan secara anaerobik tidak dapat menurunkan kandungan limbah yang terdapat di dalamnya. Hal ini terbukti dari 
penelitian sebelumnya yang mengolah POME secara anerobik. Beberapa penelitian tentang POME dapat dilihat pada Tabel 1.

Tabel 1. Beberapa Penelitian Terdahulu Mengenai Pengolahan POME secara Anerobik

\begin{tabular}{|c|c|c|}
\hline Peneliti & Tujuan & Hasil \\
\hline $\begin{array}{l}\text { Riki } \\
\text { Handoko } \\
\& \text { Alviah } \\
\text { Nadya Sari } \\
\text { Simbolon } \\
(2009)\end{array}$ & $\begin{array}{l}\text {-Close Digester } \\
\text { Tank \& suhu } \\
55^{\circ} \mathrm{C} \\
\text {-Pengaruh HRT } \\
\text { terhadap } \\
\text { fermentasi } \\
\text { POME dengan } \\
\text { variasi 4,6,8 dan } \\
10 \text { hari }\end{array}$ & $\begin{array}{l}\text {-HRT terbanyak } \\
\text { menghasilkan biogas } \\
\text { adalah HRT } 6 \text { dengan } \\
\text { laju degradasi bahan } \\
\text { organik sekitar } 75 \% \\
\text {-Laju dekomposisi bahan } \\
\text { organik terbaik } \pm 79 \% \\
\text { dicapai pada HRT } 10 \\
\text { hari }\end{array}$ \\
\hline $\begin{array}{l}\text { Vivian } \\
\text { Wongistani } \\
\text { \& M. Izni } \\
\text { Harahap } \\
\text { (2009) }\end{array}$ & $\begin{array}{ll}\text {-Variasi } & \text { HRT } \\
20,10 \& 8 & \\
\text {-Pengaruh } & \text { HRT } \\
\text { terhadap } & \\
\text { fermentasi } & \\
\text { POME } & \\
\end{array}$ & $\begin{array}{l}\text { HRT terbanyak yang } \\
\text { menghasilkan } \\
\text { adalah HRT } 8\end{array}$ \\
\hline $\begin{array}{l}\text { Jumri P } \\
\text { Pangihutan } \\
\& \\
\text { Ismaulida } \\
\text { Sari Lubis } \\
(2009) \\
\end{array}$ & $\begin{array}{lr}\text {-Variasi } & \text { lokasi } \\
\text { PKS } & \text { Pagar } \\
\text { Merbau, } & \\
\text { Rambutan } & \& \\
\text { Sisirau } & \end{array}$ & $\begin{array}{l}\text { Biogas PKS Rambutan } \\
\text { lebih baik daripada PKS } \\
\text { Merbau dan PKS Sisirau }\end{array}$ \\
\hline $\begin{array}{l}\text { Senafati \& } \\
\text { Amalia } \\
\text { Yolanda } \\
(2011) \\
\end{array}$ & $\begin{array}{lr}\text {-Variasi } & \text { recycle } \\
\text { terhadap } & \text { laju } \\
\text { dekomposisi }\end{array}$ & $\begin{array}{l}\text { Laju dekomposisi dapat } \\
\text { mencapai } 80 \%\end{array}$ \\
\hline $\begin{array}{l}\text { Febri \& } \\
\text { Vandi } \\
\text { (2011) }\end{array}$ & $\begin{array}{l}\text { Fermentasi POME } \\
\text { sistem tertutup } \\
\text { pada skala pilot }\end{array}$ & $\begin{array}{l}\text { Penyesuaian terhadap } \\
\text { kondisi operasi, loading } \\
\text { up dan sinkronisasi } \\
\text { sistem }\end{array}$ \\
\hline
\end{tabular}

Adapun proses anerobik yang dilakukan masih belum mencapai standar baku mutu yang ditetapkan agar dapat dibuang secara langsung ke lingkungan sehingga masih perlu diolah lebih lanjut dengan bantuan Effective Microorganism (EM).

\section{Teori}

Limbah cair kelapa sawit atau biasa disebut dengan Palm Oil Mill Effluent (POME) adalah cairan berwarna coklat, bersifat asam dan merupakan suspensi koloid yang mengandung komponen organik berkonsentrasi tinggi. POME berasal dari 3 sumber utama yaitu kondensat sterilisasi, klarifikasi minyak dan hydrocyclone [7].

Adapun karakteristik dari limbah cair pabrik kelapa sawit terlihat pada Tabel 2. Standar mutu limbah cair kelapa sawit supaya dapat dibuang ke badan perairan Indonesia terlihat pada Tabel 3.
Tabel 2. Karakteristik Limbah Cair Pabrik Kelapa Sawit [5]

\begin{tabular}{|c|c|c|c|}
\hline No & Parameter & Satuan & Kisaran \\
\hline 1 & $\begin{array}{ll}\text { Biological } & \text { Oxygen } \\
\text { Demand }(B O D) & \end{array}$ & $\mathrm{mg} / \mathrm{L}$ & 25.000 \\
\hline 2 & $\begin{array}{ll}\text { Chemical } & \text { Oxygen } \\
\text { Demand }(C O D) & \end{array}$ & $\mathrm{mg} / \mathrm{L}$ & 50.000 \\
\hline 3 & $\begin{array}{lll}\begin{array}{l}\text { Total } \\
(T S S)\end{array} & \text { Suspended Solid } \\
\end{array}$ & $\mathrm{mg} / \mathrm{L}$ & 18.000 \\
\hline 4 & Total Solid $(T S)$ & $\mathrm{mg} / \mathrm{L}$ & 40.500 \\
\hline 5 & $\begin{array}{l}\text { Volatile Suspended Solid } \\
\text { (VSS) }\end{array}$ & $\mathrm{mg} / \mathrm{L}$ & 34.000 \\
\hline 6 & Minyak dan Lemak & $\mathrm{mg} / \mathrm{L}$ & 4.000 \\
\hline 7 & $\mathrm{pH}$ & - & 4,7 \\
\hline
\end{tabular}

Tabel 3. Standar Mutu Limbah Cair Pabrik Kelapa Sawit [4]

\begin{tabular}{|c|c|c|}
\hline Parameter & Satuan & $\begin{array}{c}\text { Kadar } \\
\text { Maksimum }\end{array}$ \\
\hline $\mathrm{BOD}$ & $\mathrm{mg} / \mathrm{L}$ & 100 \\
\hline $\mathrm{COD}$ & $\mathrm{mg} / \mathrm{L}$ & 350 \\
\hline $\mathrm{TS}$ & $\mathrm{mg} / \mathrm{L}$ & 5.000 \\
\hline $\mathrm{TSS}$ & $\mathrm{mg} / \mathrm{L}$ & 250 \\
\hline Minyak dan Lemak & $\mathrm{mg} / \mathrm{L}$ & 25 \\
\hline $\mathrm{NH}_{3}-\mathrm{N}$ & $\mathrm{mg} / \mathrm{L}$ & 20 \\
\hline $\mathrm{pH}$ & - & $6-9$ \\
\hline $\begin{array}{c}\text { Debit Limbah } \\
\text { Maksimum }\end{array}$ & $\begin{array}{c}\mathrm{m}^{3} / \mathrm{ton} \\
\mathrm{produksi}\end{array}$ & 6 \\
\hline
\end{tabular}

Effective Microorganisms (EM) adalah campuran dari sekelompok mikroorganisme yang memiliki sifat menguntungkan bagi manusia, hewan maupun lingkungan dan di-deskripsikan sebagai multi-kultur yang terdiri dari mikroorganisme aerobik dan anaerobik yang menguntungkan. Salah satu dari keuntungan dalam penggunaan EM yaitu pengurangan volume lumpur dimana EM mengurai zat organik tersebut menjadi karbon dioksida dan metana.

Adapun Mikro-organisme yang terkandung dalam EM terdiri dari beberapa spesies yang terdiri dari bakteri asam laktat, bakteri fotosintesis, ragi, actynomycetes dan jamur fermentasi [8].

\section{Metodologi Penelitian}

Penelitian dilaksanakan di Laboratorium Departemen Teknik Kimia Fakultas Teknik USU, dan Pusdiklat LPPM USU dengan menggunakan limbah cair hasil pengolahan POME dari Pilot Plant LPPM USU dan Effective Microorganism.

Dalam pengolahan limbah secara aerobik, digunakan sebuah aerator guna menyuplai udara ke dalam reaktor. Berikut gambar yang menunjukkan reaktor dan perangkatnya yang digunakan pada penelitian ini. 


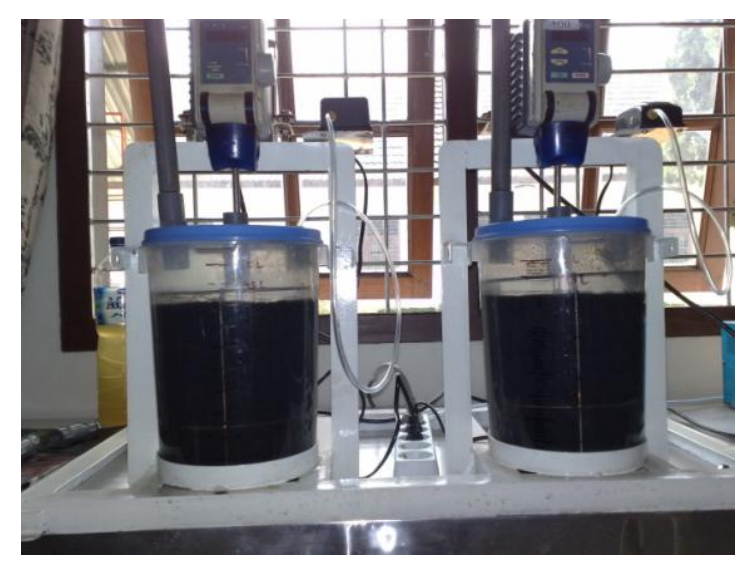

Gambar 2. Gambar Peralatan yang Digunakan.

Fungsi dari masing-masing alat yang diperlihatkan pada Gambar 2. adalah sebagai berikut :

1. Motor : Penggerak stirrer.

2. Reaktor: Wadah tempat dilakukan penelitian sampel dan EM.

3. Baffle: Untuk mencegah terjadinya pengadukan searah di dalam reaktor.

4. Stirrer : Mengaduk isi reaktor supaya terjadi pencampuran secara merata.

5. Aerator : Menyalurkan udara kedalam reaktor.

Peralatan analisa yang digunakan pada penelitian ini adalah :

1. Oven

2. Desikator

3. Cawan Penguap

4. Timbangan elektrik

5. Furnace

6. Gelas ukur

7. Beaker Glass

8. Corong Gelas

Prosedur pengaktifan Effective Microorganisms supaya dapat digunakan pada penelitian ini yaitu mula mula dipanaskan air sebanyak 4 liter dan leburkan gula aren 100 gram dalam air. Campuran kemudian didiamkan sampai suhu kamar. Kemudian ditambahkan sebanyak 40 $\mathrm{mL}$ Effective Microorganisms ke dalam campuran. Campuran tersebut ditutup rapat dan disimpan dalam ruang sejuk dan gelap selama 72 jam.

Prosedur pelaksanaan penelitian ini yaitu mula mula campuran bakteri sebanyak 2 liter dimasukkan kedalam tangki. Kemudian ditambahkan sebanyak 2 liter campuran limbah dan air dengan perbandingan 1:4 ke dalam tangki dan dihidupkan pengaduk dengan kecepatan putaran sebesar $10 \mathrm{rpm}$ pada tangki pertama dan $20 \mathrm{rpm}$ pada tangki kedua. HRT awal dimulai dengan HRT 40 hari. Prosedur diulang hingga mencapai target HRT yaitu HRT 10 hari.

\section{Hasil}

1. Penyisihan VSS tanpa menggunakan $\mathrm{EM}_{4}$

Hasil penelitian dari penyisihan VSS dengan hari yang diperoleh pada tangki tanpa penggunaan EM dapat dilihat pada Gambar 4.

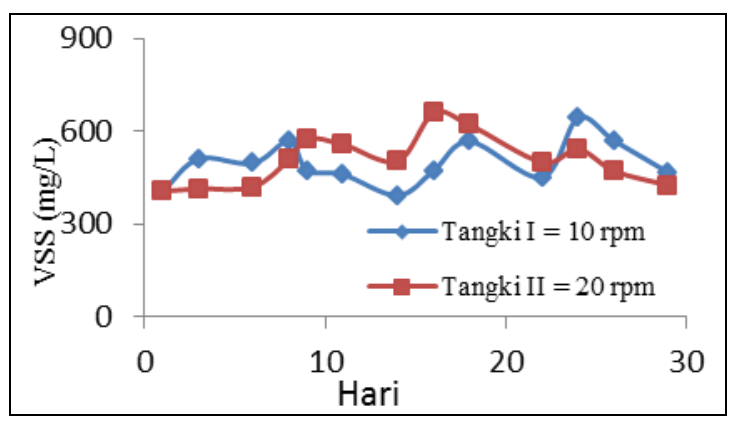

\section{Gambar 3. Grafik Penyisihan VSS tanpa $\mathbf{E M}_{4}$}

Dari gambar di atas, dapat dilihat bahwa nilai VSS pada tangki kedua awalnya cenderung lebih tinggi daripada nilai VSS pada tangki pertama tetapi pada akhirnya memiliki nilai yang lebih kecil. Hal ini disebabkan oleh oksigen yang dialirkan melalui aerasi dapat bercampur dengan baik sehingga dapat menurunkan nilai VSS dengan lebih baik [1].

2. Penyisihan VSS dengan menggunakan $\mathrm{EM}_{4}$.

Hasil penelitian dari penyisihan VSS dengan hari yang diperoleh pada tangki kedua dapat dilihat pada Gambar 5.

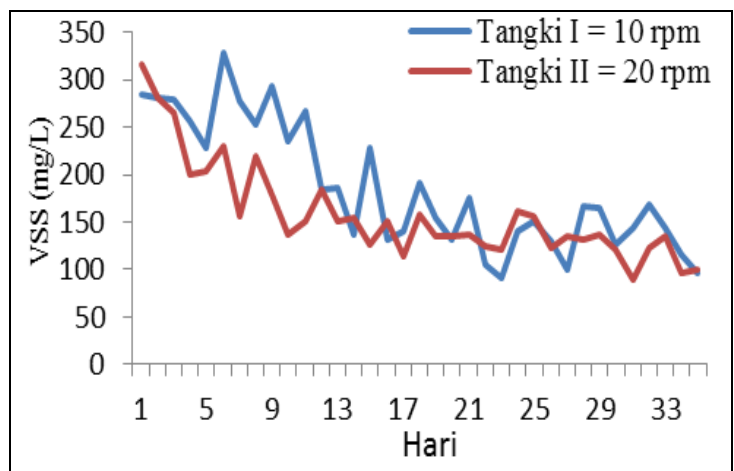

Gambar 4. Grafik Penyisihan VSS dengan $\mathrm{EM}_{4}$

Dari gambar di atas, dapat dilihat bahwa nilai VSS untuk tangki pertama cenderung lebih tinggi daripada nilai VSS untuk tangki kedua.

Berdasarkan teori yang diperoleh, diketahui bahwa semakin tinggi kecepatan pengaduk pada tangki reaktor, bakteri tidak dapat bekerja secara optimal. Hal ini disebabkan oleh pengadukan yang terlalu cepat dapat menyebabkan meledaknya sel bakteri [1]. 
3. Penyisihan COD pada Tangki dengan menggunakan $\mathrm{EM}_{4}$

Hasil penelitian dari penyisihan COD yang diperoleh pada tangki yang menggunakan EM dapat dilihat pada Gambar 5.

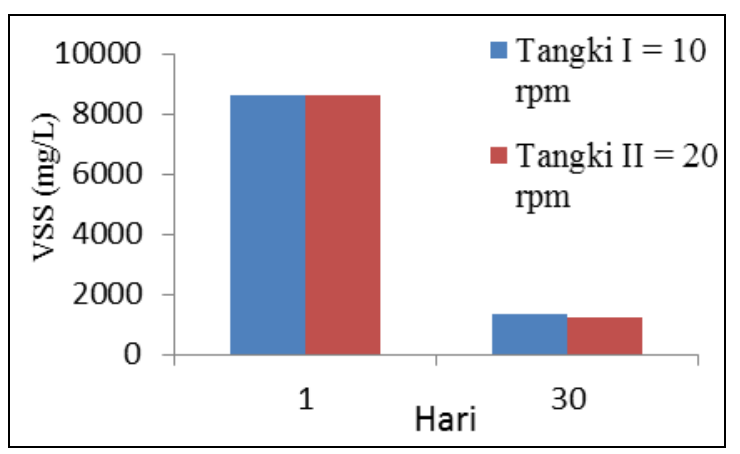

\section{Gambar 5. Grafik Penyisihan COD dengan $\mathbf{E M}_{4}$}

Dari gambar di atas, dapat dilihat bahwa nilai COD untuk tangki pertama lebih rendah daripada nilai COD untuk tangki kedua.

Berdasarkan teori yang diperoleh, dapat diketahui bahwa kecepatan pengaduk pada reaktor biologis dapat berefek negatif dan mengurangi efisiensi mikroba pada kecepatan pengadukan yang terlalu tinggi [8].

\section{Kesimpulan}

Adapun kesimpulan yang didapat dari penelitian ini adalah sebagai berikut:

1. Semakin tinggi kecepatan putaran pengaduk yang digunakan, maka nilai VSS yang diperoleh cenderung menurun.

2. Nilai VSS baik tanpa maupun dengan menggunakan $\mathrm{EM}_{4}$ cenderung menurun seiring bertambahnya hari.
3. Nilai VSS yang diperoleh dengan penggunaan $\mathrm{EM}_{4}$ cenderung lebih rendah daripada tanpa menggunakan $\mathrm{EM}_{4}$.

\section{Daftar Pustaka}

[1] Bakri, Yasser. Influence of Agitation Speeds and Aeration Rates on Xylanese Activity of Aspergillus Niger SS7. Brazilian Archives of Biology and Technology. 2011

[2] Direktorat Jenderal Perkebunan. Lintasan tiga puluh tahun pengembangan kelapa sawit. 2008.

[3] Hidayanto, M. Limbah Kelapa Sawit Sebagai Sumber Pupuk Organik dan Pakan Ternak. Balai Pengkajian Teknologi Pertanian Kalimantan Timur. Samarinda, Indonesia. 2008.

[4] Keputusan Menteri Negara Lingkungan Hidup Nomor 51 Tahun 1995.

[5] Ngan, M.A. Management of Palm Oil Industrial Effluents. Advance in Oil Palm Research Vol.2, Malaysian Palm Oil Board, Malaysia. 2000.

[6] Risza, Suyatno. Masa Depan Perkebunan Kelapa Sawit di Indonesia. Penerbit Kanisius, Yogyakarta, Indonesia. 2010.

[7] Rupani, Parveen Fatemeh, et al. Review of Current Palm Oil Mill Effluent (POME) Treatment Methods : Vermicomposting as a Sustainable Practice. Universiti Sains Malaysia, Malaysia. 2010.

[8]Szymanski, Nathan, et al. Effective Microorganism (EM) and Wastewater Systems. Published by Lanfax Laboratories Armidale. ISBN 0-9579438-1- 4 pp 347-354. 2003. 